Journal Homepage: https://topicsonchemeng.org.my/

ISBN: 978-1-948012-12-6

\title{
ANAEROBIC DIGESTION OF PULP
}

\author{
Hou Zhe sheng*, Huo Man tang, Dai Chuan bo, Wang Ben, Fang Yan zhao Xue Da liang, Li Yi \\ Power Engineering and Engineering Thermophysics, Jilin Institute of Chemical technology, Chengde Street, Jilin City, Jilin, China. \\ *Corresponding Author Email:_13844646220@126.com
}

This is an open access article distributed under the Creative Commons Attribution License, which permits unrestricted use, distribution, and reproduction in any medium, provided the original work is properly cited.

\section{ARTICLE DETAILS}

\section{Article History:}

Received 26 June 2018 Accepted 2 July 2018 Available online 1 August 2018

\section{ABSTRACT}

Alkaline pulping produces a large amount of black liquor and volatile substances, such as methanol, dimethyl sulfide, terpene, ketone, etc. It can cause serious pollution of water and air. Anaerobic inhibition with lignin in cooking is nucleophilic reaction, thus inhibiting hair lignin base and help base groups, to reduce the color of black liquor, increase the pulps whiteness, reduce the produce of the volatile matter quality at the same time. Compared with non-oxygen and aerobic cooking black liquor, the residual alkali concentration of the former was increased by $33 \%$, the PH was increased by 0.9 , the chroma decreased by $22.3 \%$, and the solids decreased by $23 \%$. In the former, the ash content of the pulp was reduced by $67 \%$, and the amount of alpha - cellulose increased by $5 \%$ and the brightness increased by $13 \%$.

\section{KEYWORDS}

Alkaline pulping, black liquor, anaerobic cooking, nucleophilic reaction.

\section{INTRODUCTION}

Util 2015, the commercial biomass of biomass energy is about 18 million tons, in addition, president $\mathrm{Xi}$ Jinping proposed that the environment is the people's livelihood, the green mountains are beautiful, the blue sky is also happy, all these require us to make reform to the industry that has a serious problem of pollution and waste of resources [1,2].

The production of alkaline pulping in China occupies $90 \%$ of the chemical pulp production $[3,4]$. This will produce large amounts of alkaline pulping black liquor, liu proposed pulping wastewater occupy our country the third of the industrial wastewater emissions $[5,6]$. He ying proposed to solve the production of black liquor and exhaust gas at the root causes, which can reduce the cost and material consumption of enterprises and reduce the pressure of corporate pollution $[7,8]$.

\section{REACTION MECHANISM}

Black liquor mechanism is: under the condition of high temperature, sodium hydroxide that does not dissolve in water polymer ether bond of lignin and benzene pyrolysis, and introduces the hydroxyl, making it easy to dissolve in water of small molecules, under aerobic conditions at the same time, the alcohol hydroxyl groups on the side chain was oxidized to carbonyl with color, in addition the methoxyl group on the lignin and $\mathrm{OH}$ , nucleophilic reaction of S2 -, methanol, dimethyl sulfide, the introduction of new phenolic hydroxyl $[6,9,10]$.

$\mathrm{ROCH}_{3}+\mathrm{Na}_{2} \mathrm{~S} \rightarrow \mathrm{CH}_{3}-\mathrm{S}-\mathrm{CH}_{3} \uparrow+\mathrm{RONa}$ (1)

$\mathrm{ROCH}_{3}+\mathrm{NaOH} \rightarrow \mathrm{CH}_{3} \mathrm{OH} \uparrow+\mathrm{RONa}(2)$

Xiao guihua suggested that oxygen concentration is an important factor affecting methanol production, and the lower the oxygen concentration is, the less methanol is produced $[6,11,12]$. To oxygen cooking process, can inhibit the nucleophilic reaction of lignin, thus inhibiting methanol, dimethyl sulfide and generate subsequent into quinone and adjacent phenol phenol oxidation of metal ion chelating agent hopson into complex reaction, dealing with pollution from the source. Industrial deoxygenation includes: atmospheric thermal deaeration, vacuum deaeration, desorption and desorption of oxygen, iron desoxygenation, oxidative resins, etc $[11,13,14]$. In this paper, the method of oxygen removal is to boil the liquid raw material into oxygen, and then to nitrogen to isolate the oxygen.

\section{EXPERIMENT}

\subsection{Raw materials, reagents and instruments}

The raw material is from the corn stalk skin of jilin city. The mill is crushed into granule and distilled water. The pressure cooker is boiling for 30min. Certain concentrations of $\mathrm{NaOH}, \mathrm{Na} 2 \mathrm{~S}, \mathrm{HCl}, \mathrm{KMnO} 2, \mathrm{BaCl} 2, \mathrm{CH} 3 \mathrm{COOH}$, $\mathrm{H} 2 \mathrm{SO} 4$, phe nolphthalein solution. Df-101s thermostatic heating magnetic stirrer, gsh-type autoclave, densitometer, constant temperature oven,crucible, analytical balance, pipette, circulating water multipurposevacuum pump.

\subsection{Experimental methods}

After cooking, and dehydration of straw particles into the cauldron, will use DF - 101 - s collection hot type constant temperature heating magnetic stirrer heating cooking for a period of time of reagent drainage into the kettle. Then tighten the end cap. After heating and holding for a period of time, add the liquid,. After a period of heat preservation, remove the solid liquid mixture.

The black liquid parameters to be determined include black liquid density, solid content, residue, $\mathrm{PH}$ and chromaticity. The methods adopted are: (1) measured with a densitometer. Copy of the same amount of black liquor, and average (2) use pipette take three $1 \mathrm{ml}$ in the conical flask black liquor were put into a beaker, and arrange in the quartz, washed with hydrochloric acid into the constant temperature oven, until the quality change, no longer take average of three (3) take $10 \mathrm{ml}$ black liquor, join the $100 \mathrm{ml}$ conical flask, add adequate $\mathrm{BaCl} 2$ solution, add distilled water diluted to scale, then let stand for a period of time, take the top $10 \mathrm{ml}$ clear night with a pipette, with $0.1 \mathrm{~mol} / \mathrm{L} \mathrm{HCl}$ titration, measure the consumption volume of $\mathrm{HCl}(4)$ black liquor $\mathrm{PH}$ value is measured with a PH meter (5) take $1 \mathrm{ml}$ black liquor, Dilute the water with distilled water 
until it is indistinguishable from the optical water, recording the dilution multiple. The above experimental results are summarized, and the parameters of the industrial cooking black liquor are listed in table 1.

Table 1: The parameters of black liquor and black liquor

\begin{tabular}{|ccccccc|}
\hline Pulping & & \multicolumn{4}{c|}{ Residual alkali } \\
method & Density g/L & Solid content g/L & g/L & PH & Chroma \\
\hline Aerobic & 1055 & 140 & 11.87 & 11.6 & 20600 \\
& 1042 & 107.84 & 16.02 & 13 & 16000 \\
& 1031 & 105.76 & 16.45 & 12.5 & 16000 \\
Anaerobic & 1047 & 109.72 & 15.01 & 12 & 16000 \\
& & & & & \\
\hline
\end{tabular}

The paper pulp parameters that need to be determined include the pulp yield and the important parameters of the pulp quality. The methods adopted are: (1) to tear, cooking exp eriment of the proceeds of the pulp into petri dishes, put into the set temperature for $1 \mathrm{~h}$ in the $100-105{ }^{\circ} \mathrm{C}$ oven thermostat, measurement, calculation of pulp yield pulp, (2) take $1 \mathrm{~g}$ in the crucible heated, then put into the set temperature is $600{ }^{\circ} \mathrm{C}$ high temperature box, using analytical balance to measure quality, calculation of ash content (3) the torn pieces of paper pulp soaking with a certain concentration of $\mathrm{NaOH}$, mercerizing, then under the condition of suction, solution with $\mathrm{NaOH}$ solution washing three times, then washing with distilled water, $\mathrm{CH} 3 \mathrm{COOH}$ solution soak, then washing with distilled water, until the pulp to neutral (4) the pulp is vacuum suction, Contrast with the PANTONE color card by drying the oven and comparing the results with the computer standard color. The contrast results are shown in Figure 1. The above experimental results are summarized, and the parameters of industrial cooking paper are listed in table 2.
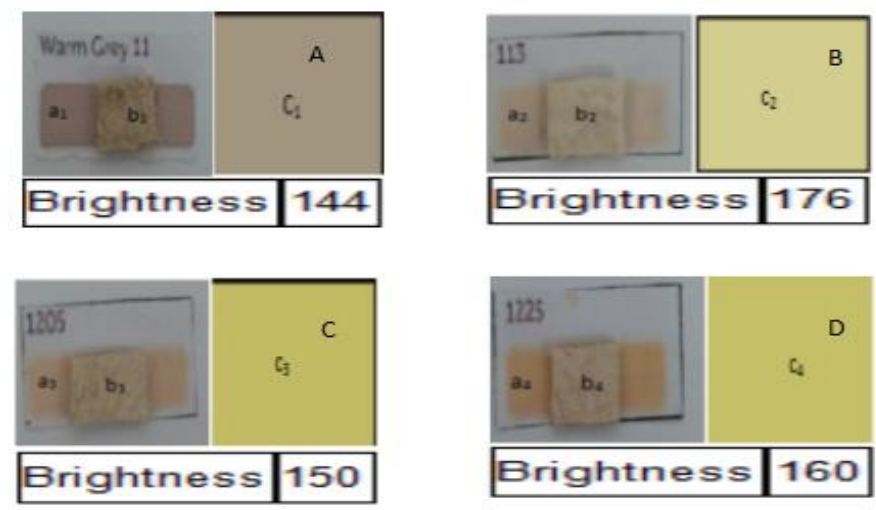

Figure 1: Comparison of aerobic cooking pulp and anaerobic cooking pulp with PANTONG color card

(A)Aerobic cooking(B)Liquid ratio is 1:4 anaerobic cooking(C)Liquid ratio is $1: 4$ anaerobic cooking(D)Liquid ratio is $1: 4$ anaerobic cooking

Notes $\mathrm{a}_{1} 、 \mathrm{a}_{2} 、 \mathrm{a}_{3}, \mathrm{a}_{4}$ are pulp samples, $\mathrm{b}_{1} 、 \mathrm{~b}_{2}, \mathrm{~b}_{3}, \mathrm{~b}_{4}$ are PANTON color card sample, $c_{1} 、 c_{2} 、 c_{3} 、 c_{4}$ are computer color specs.

Table 2: The parameters of anaerobic digester and aerobic digester

\begin{tabular}{|ccccc|}
\hline $\begin{array}{c}\text { Pulping } \\
\text { method }\end{array}$ & Pulp yield \% & Ash \% & $\begin{array}{c}\text { Alpha-cellulose } \\
\text { content \% }\end{array}$ & Brightness \\
\hline Aerobic & 50 & 3.5 & 80 & 144 \\
& 45.16 & 1.14 & 72 & 206 \\
Anaerobic & 46.01 & 1.26 & 85 & 193 \\
& 45.68 & 1.07 & 83 & 185 \\
\hline
\end{tabular}

\section{RESULTS AND DISCUSSION}

By Table 1 we can calculate the average of each parameter of the black liquid, (1) under the anaerobic condition of black liquor density from 1055 $\mathrm{g} / \mathrm{L}$ to $1044 \mathrm{~g} / \mathrm{L}$ changed little, solid content from $140 \mathrm{~g} / \mathrm{L}$ to $107 \mathrm{~g} / \mathrm{L}$, levels fell by $23 \%$, down a lot, inhibit the phenol hydroxyl generation anaerobic conditions, reduce $22.3 \%$ lower lignin (2) the chromaticity of the soluble in water, for two reasons, one is water soluble lignin decreases, the second is inhibits the formation of phenolic hydroxyl anaerobic conditions, reduce the lignin oxidation into quinone and elevated and $\mathrm{Fe} 3$ + chelating (3) the residual alkali concentration 33\%, PH 0.9, anaerobic conditions inhibit the nucleophilic reaction, reduce the consumption of $\mathrm{OH}$ - It is shown that there is less alkali needed to make pulps without oxygen, and it can reduce the amount of alkali used in cooking, so as to save cost.

Under anaerobic conditions for cooking, pulp yield fell by $4.84 \%$, ash reduced by $67 \%$, alpha cellulose content increased by $5 \%, 13 \%$ brighter.Low ash pulp, pulp quality is good, anaerobic cooking that can greatly improve the quality of the pulp. Alpha cellulose content is an important index to measure the pulp quality, the high content of alpha cellulose, performance is good, the pulp drainability and copying anaerobic cooking than general industrial high cooking the alpha cellulose pulp, anaerobic cooking pulp quality is good. Anaerobic cooking pulp whiteness, high balanced dissolved lignin in cooking phase, compared with the industrial steam the adsorption quantity on cellulose roughly equal, but because in the black liquor lignin base group is less, can largely improve the whiteness of pulp. Pulp yield is low because hemicellulose is more soluble.

\section{CONCLUSION}

Nucleophilic reaction of lignin and subsequent oxidation is a major cause of pulping process contamination, oxygen free cooking by oxygen can effectively restrain the two reaction, so as to reduce the production of waste gas, to a great extent at the same time also can reduce the black liquor chromaticity, improve the quality of pulp, pulp whiteness, drug use, thereby reducing the bleaching process reduces the pollution of bleaching. The development of anaerobic cooking is of great significance to the existing pulping industry.

\section{ACKNOWLEDGMENTS}

Fund Project : Significant Scientific and Technical Project in Jilin（20170201003GX）

\section{REFERENCES}

[1] NEA. 2016. Biomass energy development of the 13th five-year plan. National energy administration.

[2] Guo, J.K., Jinping's, X. 2015. Environment is the people's livelihood. Speaking of people's hearts and minds [N]. People's Daily online, 03-08.

[3] Lin, W.Y. 2003. Current situation and development prospect of alkaline pulping technology in China's paper industry [J]. China paper, 22 (9).

[4] Zang, J., Shen, X.D. 2013. Study on the preparation of high-efficiency water reducing agent by the modification of alkali lignin deoxygenation [J]. New building materials, 7, 66-68.

[5] Liu, M. 2008. Treatment of black liquor in pulping and papermaking process [J]. Guangxi light industry, 10, 103-104.

[6] Xiao, G.H., Liu, Q., Jjuan, Wen, J.Y. 2015. The effect of treatment conditions on the production of methanol by the treatment conditions of birch cooking black liquor. China paper, 34 (2), 14-18.

[7] Pu, S.C., Feng, Q.M. 2008. Current situation of water pollution in China and countermeasures [J]. Comprehensive utilization of Chinese resources, (5), 31-34 
[8] He, Y., He, A.Y. 2007. Characteristics of small and medium-sized enterprises on the impact and solution of pollution control [J]. Economist, (1), 205-206.

[9] Sun, L. 2012. Degradation of lignin by catalytic hydrogenation [D]. Beijing: Beijing university of chemical technology.

[10] Li, Y.M., Chen, G.H. 1994. Hair color effect of lignin Na2SO3 treatment [J]. Journal of Chinese papermaking, 19.

[11] Zhao, H. 1996. On the texture and changes of the raw materials and pulp of pulp in pulping [J]. Gansu light textile technology, (4)
[12] Xi, W., Li, X.P. 2008. Hydrogen peroxide and beta - 0 - 4 lignin quinoid hair base group response characteristics research flat [J]. Journal of the Chinese paper industry, 16, 32-35.

[13] Lu, W.S., Yao, W.T., Song, Z. 2005. Analysis on the way of oxygen removal in industrial boilers [J]. Henan metallurgy, 6, 52-54+26.

[14] Aldaihani, N. 2017. Estimation of CO2 Emissions of The Vehicles Transport Sector In The State Of Kuwait. Acta Chemica Malaysia, 1 (1), 0812.

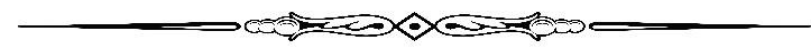

